\title{
Acute Effects of Summer Air Pollution on Pulmonary Function and Airway Inflammation in Healthy Young Women
}

\author{
Yoshiko Yoda ${ }^{1}$, Naruhito Otani ${ }^{1}$, Shiro Sakurai ${ }^{2}$, and Masayuki Shima ${ }^{1}$ \\ ${ }^{1}$ Department of Public Health, Hyogo College of Medicine, Nishinomiya, Hyogo, Japan \\ ${ }^{2}$ Department of Environmental Science, School of Social Information Studies, Otsuma Women's University, Tama, Tokyo, Japan
}

Received October 16, 2013; accepted March 2, 2014; released online May 24, 2014

Copyright $(\odot 2014$ Yoshiko Yoda et al. This is an open access article distributed under the terms of Creative Commons Attribution License, which permits unrestricted use, distribution, and reproduction in any medium, provided the original author and source are credited.

\begin{abstract}
Background: Exposure to air pollution has been reported to be associated with asthma exacerbation. However, little is known about the effects of air pollutant exposure in healthy people. A panel study was conducted to evaluate the acute effects of air pollutants on pulmonary function and airway inflammation in healthy subjects.

Methods: Exhaled breath condensate (EBC) pH, fractional concentration of exhaled nitric oxide (FeNO), and pulmonary function were measured in 21 healthy young women repeatedly for two weeks in the summer in Tokyo, Japan. The concentrations of air pollutants were obtained from the monitoring stations in the neighborhoods where the subjects lived. Statistical analyses were performed using generalized estimating equations.

Results: EBC pH decreased significantly with a 10-ppb increase in the 4-day average ozone $\left(\mathrm{O}_{3}\right)$ concentration and a $10-\mu \mathrm{g} / \mathrm{m}^{3}$ increase in the 4-day average suspended particulate matter (SPM) concentration $(-0.07$ [95\% confidence interval $\{\mathrm{CI}\}-0.11$ to -0.03$]$ and -0.08 [95\% CI -0.12 to -0.03$]$, respectively). Subjects with a history of rhinitis showed marked decreases in EBC pH associated with increases in $\mathrm{O}_{3}$ and SPM. The changes in forced expiratory volume in 1 second $\left(\mathrm{FEV}_{1}\right)$ were also significantly associated with a $10-\mu \mathrm{g} / \mathrm{m}^{3}$ increase in the 3-day average concentration of SPM $(-0.09 \mathrm{~L}$ [ $95 \% \mathrm{CI}-0.17$ to -0.01$])$. FeNO increased significantly in relation to the increase in $\mathrm{O}_{3}$ and SPM among only subjects with a history of asthma.

Conclusions: Over the course of the study, EBC became significantly acidic with increases in $\mathrm{O}_{3}$ and SPM concentrations. Furthermore, higher SPM concentrations were associated with decreased $\mathrm{FEV}_{1}$. Subjects with a history of rhinitis or asthma are considered to be more susceptible to air pollutants.
\end{abstract}

Key words: airway inflammation; exhaled breath condensate; ozone; particulate matter; pulmonary function

\section{INTRODUCTION}

The acute effects of air pollution on respiratory symptoms have been widely reported. ${ }^{1,2}$ Many studies have shown that ambient air pollution, especially particulate matter, is associated with effects on respiratory symptoms and exacerbation of asthma. ${ }^{3-9}$ Ozone $\left(\mathrm{O}_{3}\right)$ is also a major air pollutant, and studies have reported that high concentrations of ozone in summer affect respiratory symptoms in subjects with asthma. ${ }^{10-13}$ Berhane et al showed that a short-term increase in $\mathrm{O}_{3}$ concentration was related to airway inflammation in children. ${ }^{14}$ In addition, elevated $\mathrm{O}_{3}$ levels were reported to be associated with airway inflammation in atopic participants, both with and without asthma. ${ }^{15}$ While some findings have shown the acute effects of $\mathrm{O}_{3}$ on respiratory symptoms, the pathophysiological mechanisms for the effects of $\mathrm{O}_{3}$ are not fully understood.

In recent years, the measurement of the fractional concentration of nitric oxide in exhaled air (FeNO) has become valuable for the noninvasive and quantitative assessment of airway inflammation. ${ }^{16}$ Exhaled breath condensate (EBC) is also used as an indicator of oxidative stress. ${ }^{17}$ Since these assays are simple and can be performed repeatedly, they are considered to be useful for evaluating airway inflammation in epidemiologic studies. Using these methods, the acute effects of air pollutants on airway inflammation have been evaluated in asthmatic children and adolescents. ${ }^{18,19}$

Most previous studies have reported the acute effects of air pollution in children and patients with asthma, but few studies 
have investigated the effects in healthy adults. The aim of this study was to investigate whether rising concentrations of air pollutants have an acute effect on the respiratory system in healthy adult subjects. Therefore, tests of pulmonary function and the inflammatory condition of the airways were repeatedly performed in 21 healthy female students, and the potential effects of air pollution in the summer season, when a large variation in the concentrations of air pollutants was forecasted, were evaluated.

\section{METHODS}

\section{Study design and subjects}

A panel study was conducted for two weeks in July 2012. The subjects of this study were 21 healthy female students, aged 20-23 years, who had to commute to a university in Tokyo, Japan. They were recruited from among non-smoking students who attended several seminars in their third or fourth year. The university is located in a suburban area in Tokyo, and all of the study subjects lived in the Tokyo metropolitan area. The study protocol was approved by the Ethics Committee of Hyogo College of Medicine. The objective and method of this study were fully explained to the subjects, and written informed consent was obtained from each subject before the study.

At the beginning of the study, respiratory symptoms, medical history, family history, and smoking habits were evaluated by a modified ATS-DLD-78 questionnaire. ${ }^{20}$ The subjects were also asked to record their daily movements during the study period. Measurements of pulmonary function and airway inflammation were repeated four times during the study period and were performed on the same day for all subjects. Subjects were requested to refrain from eating and drinking for 2 hours before measurements in order to not affect the results of the tests. The order of testing was FeNO measurement, pulmonary function tests, and collection of EBC.

\section{Sampling of exhaled air and measurement of FeNO}

The FeNO levels were measured using the off-line method according to ATS/ERS recommendations. ${ }^{16}$ The subjects inspired maximally in the seated position, and then they exhaled into a 1.5-L Mylar bag (Sievers Instruments, Inc., Boulder, CO, USA) to keep the mouth pressure constant at $15 \mathrm{cmH}_{2} \mathrm{O}$ and the expiratory flow rate at $50 \mathrm{~mL} / \mathrm{s}$. Exhaled air of the first 10 seconds $(500 \mathrm{~mL})$ was discarded to prevent contamination by NO from the nasal cavity and upper airway. The collection was repeated three times for each subject. The bag samples were stored at $4^{\circ} \mathrm{C}$ until analysis, and FeNO was measured using a chemiluminescence NO analyzer (Model NA-623N; Kimoto Electric Co., Ltd., Osaka, Japan) within 24 hours after collection. ${ }^{21}$ The analyzer was calibrated daily using zero-gas and standard NO gas (735 ppb). The values of FeNO are shown as the means of three samples. If the deviation for each set of triplicate samples was larger than
$20 \%$ of the mean, the highest FeNO value was removed from the calculation of the mean.

\section{Pulmonary function tests}

Pulmonary function tests were performed using an electronic expiratory flow meter (Vitalograph 2110; Vitalograph Ltd., Buckingham, UK). Before beginning the testing, the device was calibrated using a 3-L syringe. Peak expiratory flow (PEF) and forced expiratory volume in 1 second $\left(\mathrm{FEV}_{1}\right)$ were measured four times for all subjects. For each measurement, the highest PEF and $\mathrm{FEV}_{1}$ values were selected from more than two reproducible maneuvers.

\section{Exhaled breath condensate collection}

EBC was collected using an RTube device (Respiratory Research Inc., Charlottesville, VA, USA) during $15 \mathrm{~min}$ of quiet breathing while wearing a nose clip. Approximately $1.5 \mathrm{~mL}$ of EBC sample was obtained. Immediately after collection, the obtained sample was divided into two aliquots. One sample was degassed with argon gas at a flow rate of $300 \mathrm{~mL} / \mathrm{min}$ bubbling. The $\mathrm{pH}$ of EBC was then measured using a pH meter (F-52; HORIBA, Ltd., Kyoto, Japan). Another sample was stored at $-80^{\circ} \mathrm{C}$ until measurement of 8isoprostane, which is an oxidative stress marker. 8-isoprostane concentrations were measured using a specific enzyme-linked immunosorbent assay (Cayman Chemical Company, Ann Arbor, MI, USA). The lower limit of detection of this assay was $2.7 \mathrm{pg} / \mathrm{mL}$. Unfortunately, the values of 8 -isoprostane in EBC were below the detection limit in most samples, although the values were detected in some samples. Thus, the 8-isoprostane values could not be used as an oxidative stress marker.

\section{Air pollution monitoring}

The concentrations of air pollutants and the meteorological data at the monitoring stations in the neighborhoods where the subjects lived were obtained from the Atmospheric Environmental Regional Observation System of the Ministry of the Environment, Japan. If the meteorological data were unavailable at the monitoring stations, they were obtained from the Japan Meteorological Agency. The 24-hour averages of suspended particulate matter (SPM), nitrogen dioxide $\left(\mathrm{NO}_{2}\right)$, and $\mathrm{O}_{3}$ concentrations, temperature, and relative humidity were used. In Japan, SPM is defined under the Japanese Air Quality Standard as particles with an aerodynamic diameter of $\leq 10 \mu \mathrm{m}$ by the $100 \%$ cutoff point, which corresponds approximately to particulate matter $<7 \mu \mathrm{m}$ in aerodynamic diameter by the $50 \%$ cutoff point. ${ }^{22}$ The distances between the subjects' residences and the monitoring stations were 0.2 to $8.3 \mathrm{~km}$, and there was no significant difference in the surrounding environment.

\section{Statistical analysis}

Since the FeNO level was roughly log-normally distributed, 
logarithms of the measurements were used for analysis. The measurements of EBC $\mathrm{pH}, \log \mathrm{FeNO}, \mathrm{PEF}$, and $\mathrm{FEV}_{1}$ were examined in relation to the concentrations of air pollutants. For regression analyses of the measurements, the Generalized Estimating Equation (GEE) ${ }^{23}$ was used, which is suitable for correlated data in individual repeated measures. The standard error of the regression estimate was adjusted for possible correlation among outcomes from a single subject. After adjusting for temperature and relative humidity, we calculated mean changes and $95 \%$ confidence intervals (CIs) in $\mathrm{EBC} \mathrm{pH}$, FeNO, PEF, and $\mathrm{FEV}_{1}$ for $10-\mu \mathrm{g} / \mathrm{m}^{3}$ increases in $\mathrm{SPM}$ or 10 -ppb increases in $\mathrm{O}_{3}$ or $\mathrm{NO}_{2}$.

The average concentrations of each pollutant during the 24 hours preceding measurement were used as exposure variables. In order to assess the potentially delayed effects of air pollutants, the concentration for the previous day and 2- to 5-day averages were also examined. Next, because the sensitivity to air pollutants may differ in relation to respiratory symptoms, the participants were stratified by the presence or absence of a history of rhinitis or asthma. The changes in EBC $\mathrm{pH}, \mathrm{FeNO}, \mathrm{PEF}$, and $\mathrm{FEV}_{1}$ associated with 4-day averages of $\mathrm{O}_{3}$ and SPM were estimated, because they showed the greatest changes in the analyses involving all subjects. Furthermore, the analyses were performed using two-pollutant models to adjust for potential confounding effects of co-pollutants using the 4-day averages of each pollutant.
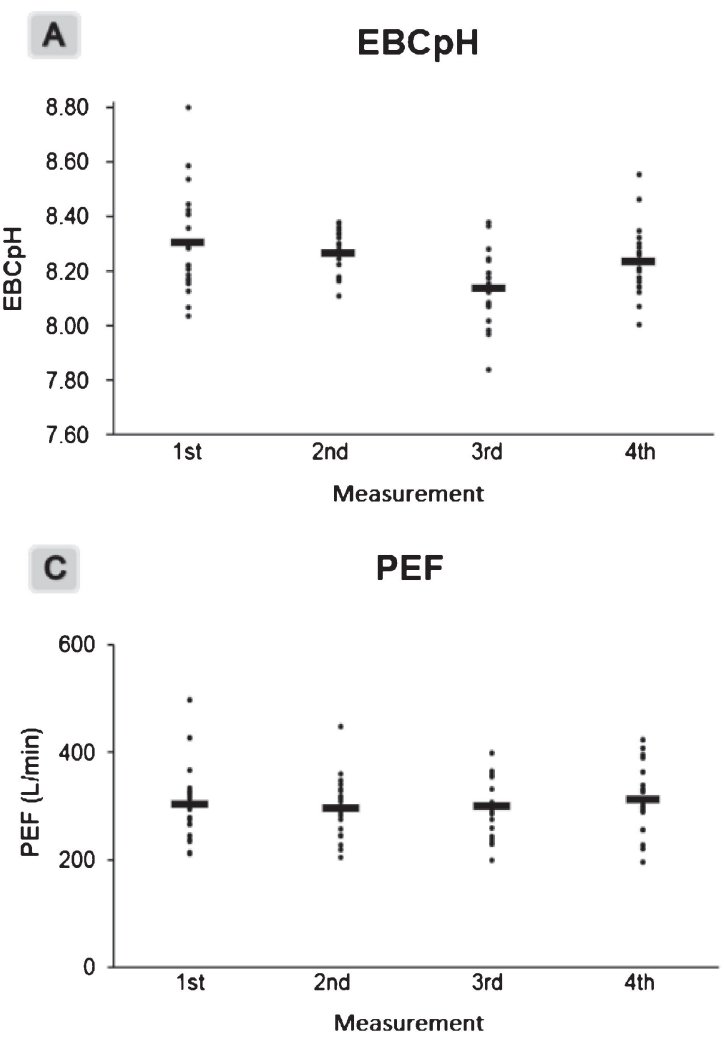

All statistical analyses were performed using SPSS version 19 (IBM Co., Armonk, NY, USA). A two-tailed value of $P<0.05$ was considered significant.

\section{RESULTS}

Table 1 presents the characteristics of the study subjects. A total of 21 healthy non-smoking subjects took part in the study. The results of pulmonary function tests and airway inflammation tests are shown in Figure 1. A total of 84 samples of FeNO, PEF, and $\mathrm{FEV}_{1}$ were collected, and 83 samples of EBC were collected, because one sample was contaminated by saliva. The average EBC $\mathrm{pH}$ was slightly lower in the samples collected the third time than at other times. The average PEF was slightly lower the second time and highest the fourth time.

Table 1. Characteristics of study subjects

\begin{tabular}{ll}
\hline & Total $(n=21)$ \\
\hline Age, mean (SD) (years) & $21.0(0.6)$ \\
Height, mean (SD) (cm) & $158.8(5.9)$ \\
History of asthma (yes/no) & $4 / 17$ \\
History of rhinitis (yes/no) & $12 / 9$ \\
History of pollinosis (yes/no) & $8 / 13$ \\
\hline
\end{tabular}

SD, Standard deviation.

B
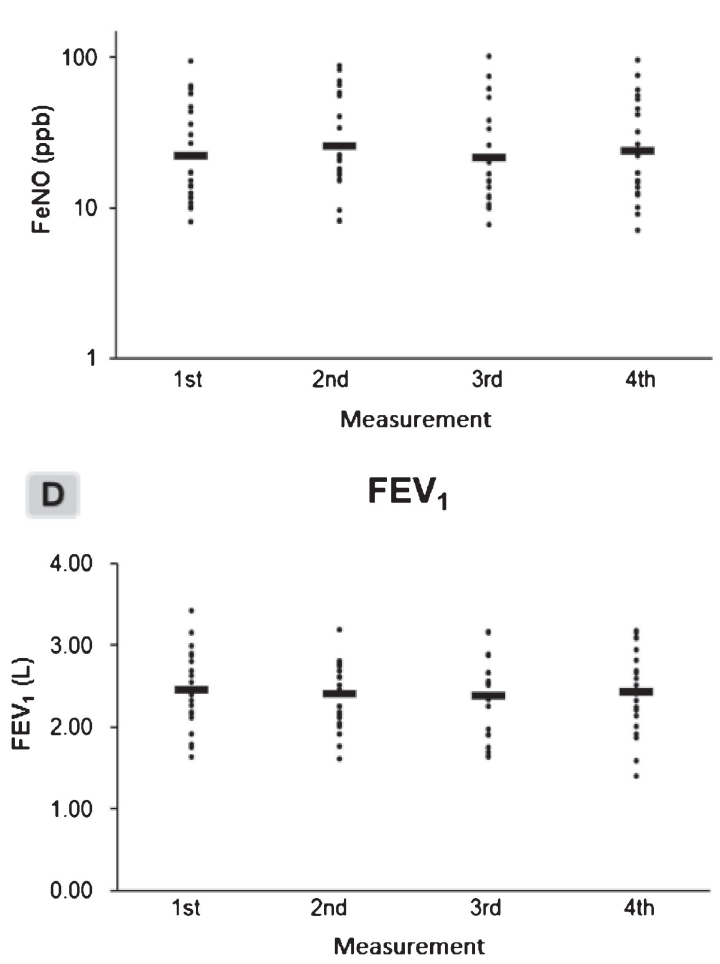

Figure 1. Distributions of the results of $E B C p H(A), F e N O(B), P E F(C)$, and $F E V_{1}(D)$ for each of the four measurements. Horizontal bars represent the means of each test. The results of FeNO (B) are plotted on a logarithmic scale, and the bars show the geometric means. 

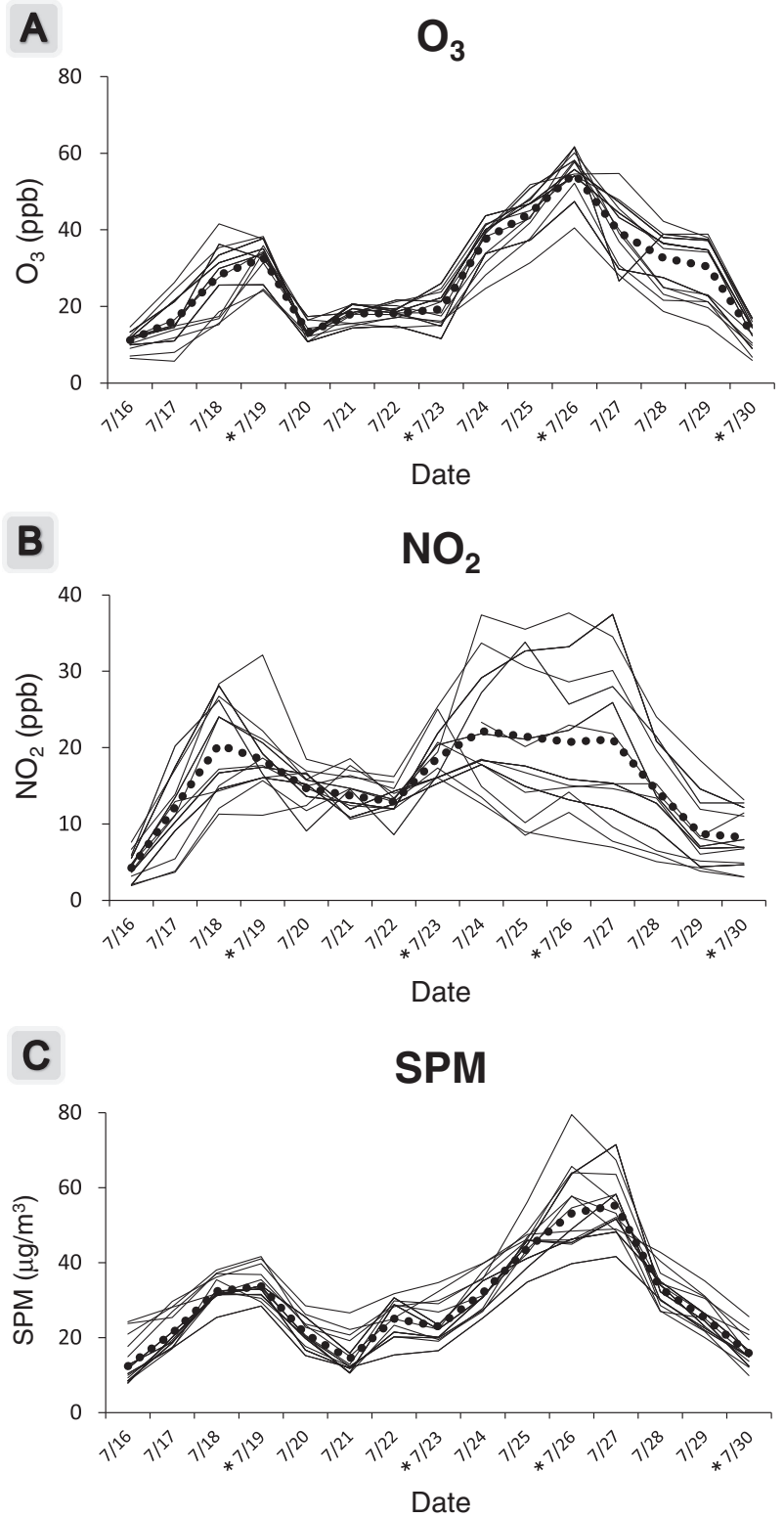

Figure 2. The 24-hour mean concentrations of $\mathrm{O}_{3}(\mathrm{~A})$, $\mathrm{NO}_{2}(\mathrm{~B})$, and SPM $(\mathrm{C})$ for each subject during the study period. The dotted lines show the daily average concentrations of each pollutant for all subjects. *Respiratory function tests were conducted on these days.

Daily average concentrations of air pollutants during this study period are shown in Figure 2. The concentrations of $\mathrm{O}_{3}$ and SPM were highest on 26 July, when the third pulmonary function test was conducted. The concentration of $\mathrm{NO}_{2}$ differed considerably by the residence of the subjects, but the concentrations of $\mathrm{O}_{3}$ and SPM did not differ by the subjects' residence. Table 2 shows the correlation coefficients of the concentrations of air pollutants; concentrations of $\mathrm{O}_{3}$, $\mathrm{NO}_{2}$, and SPM were correlated with each other.

Table 3 shows the changes in EBC pH, FeNO, PEF, and $\mathrm{FEV}_{1}$ associated with a $10-\mu \mathrm{g} / \mathrm{m}^{3}$ or $10-\mathrm{ppb}$ increase in the concentration of each pollutant, using single-pollutant models
Table 2. Correlation coefficients of air pollutants and meteorological factors

\begin{tabular}{lccccc} 
& $\mathrm{O}_{3}$ & $\mathrm{NO}_{2}$ & $\mathrm{SPM}$ & Temperature & $\begin{array}{c}\text { Relative } \\
\text { humidity }\end{array}$ \\
\hline $\mathrm{O}_{3}$ & 1 & $0.715^{*}$ & $0.909^{*}$ & 0.459 & -0.286 \\
$\mathrm{NO}_{2}$ & & 1 & $0.752^{*}$ & 0.042 & 0.076 \\
$\mathrm{SPM}$ & & & 1 & 0.431 & -0.227 \\
Temperature & & & & 1 & $-0.925^{*}$ \\
Relative humidity & & & & & 1 \\
\hline
\end{tabular}

$\mathrm{O}_{3}$, ozone; $\mathrm{NO}_{2}$, nitrogen dioxide; SPM, suspended particulate matter. Pearson's correlation coefficients were calculated using the means of daily average concentrations of air pollutants or meteorological factors for each subject. $* P<0.01$.

adjusted for temperature and relative humidity. The change in EBC $\mathrm{pH}$ was significantly negatively associated with the concentrations of both $\mathrm{O}_{3}$ and SPM; in particular, the change was greatest in relation to the 4-day average concentration of $\mathrm{O}_{3}$ and SPM $(-0.07$ [95\% CI -0.11 to -0.03 ] and -0.08 [95\% CI -0.12 to -0.03$]$, respectively). The change in FeNO was not associated with $\mathrm{O}_{3}, \mathrm{NO}_{2}$, or SPM. The change in $\mathrm{FEV}_{1}$ was negatively associated with the 3-day average concentration of SPM $(-0.09 \mathrm{~L}[95 \% \mathrm{CI},-0.17$ to -0.01$])$. PEF was not significantly associated with any pollutants. The results of the analyses excluding the four subjects who lived more than $5 \mathrm{~km}$ from the monitoring stations are shown in eTable 1. The effects of $\mathrm{O}_{3}$ on $\mathrm{EBC} \mathrm{pH}$ were similar to the results of the analyses of all subjects. In addition, as a sensitivity analysis, the data were reanalyzed excluding outliers for each pulmonary function. The results showed similar patterns of the effects of pollutants as with the full data set (results not shown).

After the participants were stratified by the presence or absence of a history of rhinitis or asthma, the changes in EBC $\mathrm{pH}, \mathrm{FeNO}, \mathrm{PEF}$, and $\mathrm{FEV}_{1}$ in relation to increases in the 4-day average concentration of air pollutants are shown in Figure 3. Among subjects who had a history of rhinitis, increases in $\mathrm{O}_{3}$ and SPM concentrations were significantly associated with low $\mathrm{EBC} \mathrm{pH}$. However, no association was seen in subjects without a history of rhinitis. On the other hand, $\mathrm{FEV}_{1}$ decreased significantly with increases in SPM concentrations among subjects without a history of rhinitis. EBC $\mathrm{pH}$ significantly decreased with increases in $\mathrm{O}_{3}$ or SPM concentrations only among subjects without a history of asthma (Figure 3a). FeNO levels were significantly higher with increases in $\mathrm{O}_{3}$ and SPM concentrations among subjects with a history of asthma (Figure 3b). PEF was associated with neither $\mathrm{O}_{3}$ nor SPM, regardless of the presence of rhinitis or asthma (Figure $3 \mathrm{c}$ ). $\mathrm{FEV}_{1}$ showed significant decreases with high concentrations of $\mathrm{O}_{3}$ and SPM only among subjects with a history of asthma (Figure 3d).

Two-pollutant models were also tested to adjust for confounding effects of co-pollutants. Table 4 shows the changes in EBC pH, FeNO, PEF, and $\mathrm{FEV}_{1}$ associated with 
Table 3. Estimated changes and $95 \%$ Cls in respiratory function test results per $10-\mu \mathrm{g} / \mathrm{m}^{3}$ or $10-\mathrm{ppb}$ increase in each pollutant during the study period

\begin{tabular}{|c|c|c|c|c|c|c|c|c|c|c|c|c|}
\hline & \multicolumn{3}{|c|}{$\mathrm{EBC} \mathrm{pH}$} & \multicolumn{3}{|c|}{$\log \mathrm{FeNO}$} & \multicolumn{3}{|c|}{ PEF (L/min) } & \multicolumn{3}{|c|}{$\mathrm{FEV}_{1}(\mathrm{~L})$} \\
\hline & Change & $95 \% \mathrm{Cl}$ & $P$ value & Change & $95 \% \mathrm{Cl}$ & $P$ value & Change & $95 \% \mathrm{Cl}$ & $P$ value & Change & $95 \% \mathrm{Cl}$ & $P$ value \\
\hline \multicolumn{13}{|l|}{$\mathrm{O}_{3}$} \\
\hline Test day ${ }^{a}$ & -0.02 & $(-0.04,0.00)$ & 0.024 & 0.02 & $(-0.05,0.08)$ & 0.623 & -3.16 & $(-9.71,3.40)$ & 0.346 & -0.02 & $(-0.06,0.03)$ & 0.489 \\
\hline Previous day ${ }^{b}$ & -0.04 & $(-0.08,0.00)$ & 0.026 & 0.07 & $(-0.11,0.25)$ & 0.427 & 2.82 & $(-14.64,20.29)$ & 0.752 & 0.00 & $(-0.15,0.15)$ & 0.977 \\
\hline 2-day average ${ }^{c}$ & -0.04 & $(-0.06,-0.01)$ & 0.014 & 0.03 & $(-0.08,0.13)$ & 0.612 & -1.61 & $(-12.24,9.01)$ & 0.766 & -0.01 & $(-0.09,0.07)$ & 0.783 \\
\hline 3-day average ${ }^{d}$ & -0.05 & $(-0.09,-0.02)$ & 0.003 & 0.02 & $(-0.10,0.15)$ & 0.711 & 1.31 & $(-10.57,13.19)$ & 0.829 & 0.00 & $(-0.10,0.10)$ & 0.948 \\
\hline 4-day average ${ }^{d}$ & -0.07 & $(-0.11,-0.03)$ & 0.001 & 0.00 & $(-0.18,0.18)$ & 0.999 & 5.64 & $(-8.69,19.98)$ & 0.440 & 0.01 & $(-0.12,0.14)$ & 0.880 \\
\hline 5-day average ${ }^{d}$ & -0.06 & $(-0.11,-0.02)$ & 0.003 & -0.04 & $(-0.23,0.15)$ & 0.659 & 12.14 & $(-3.45,27.74)$ & 0.127 & 0.04 & $(-0.10,0.18)$ & 0.610 \\
\hline \multicolumn{13}{|l|}{$\mathrm{NO}_{2}$} \\
\hline Test day ${ }^{a}$ & -0.01 & $(-0.04,0.01)$ & 0.375 & -0.13 & $(-0.34,0.08)$ & 0.214 & -6.23 & $(-22.17,9.71)$ & 0.444 & 0.04 & $(-0.12,0.21)$ & 0.618 \\
\hline Previous day ${ }^{b}$ & 0.01 & $(-0.02,0.03)$ & 0.614 & -0.07 & $(-0.26,0.13)$ & 0.517 & -13.13 & $(-28.99,2.72)$ & 0.104 & 0.03 & $(-0.12,0.18)$ & 0.671 \\
\hline 2-day average ${ }^{c}$ & 0.00 & $(-0.03,0.02)$ & 0.893 & -0.10 & $(-0.31,0.12)$ & 0.373 & -10.77 & $(-27.60,6.06)$ & 0.210 & 0.04 & $(-0.13,0.20)$ & 0.645 \\
\hline 3-day average ${ }^{d}$ & -0.01 & $(-0.04,0.02)$ & 0.492 & -0.11 & $(-0.37,0.16)$ & 0.430 & -13.55 & $(-33.87,6.78)$ & 0.192 & 0.05 & $(-0.15,0.24)$ & 0.656 \\
\hline 4-day average ${ }^{d}$ & -0.01 & $(-0.05,0.03)$ & 0.479 & -0.21 & $(-0.52,0.11)$ & 0.200 & -5.41 & $(-30.41,19.59)$ & 0.672 & 0.10 & $(-0.13,0.33)$ & 0.401 \\
\hline 5-day average ${ }^{d}$ & -0.01 & $(-0.06,0.04)$ & 0.684 & -0.31 & $(-0.67,0.04)$ & 0.084 & -0.14 & $(-30.78,30.49)$ & 0.993 & 0.14 & $(-0.13,0.40)$ & 0.314 \\
\hline \multicolumn{13}{|l|}{ SPM } \\
\hline Test day ${ }^{a}$ & -0.02 & $(-0.04,0.00)$ & 0.019 & -0.01 & $(-0.06,0.05)$ & 0.848 & -2.53 & $(-10.29,5.22)$ & 0.522 & -0.04 & $(-0.08,0.01)$ & 0.129 \\
\hline Previous day ${ }^{b}$ & -0.05 & $(-0.08,-0.02)$ & 0.001 & 0.03 & $(-0.08,0.15)$ & 0.573 & -5.87 & $(-18.45,6.71)$ & 0.360 & -0.07 & $(-0.15,0.01)$ & 0.096 \\
\hline 2-day average ${ }^{c}$ & -0.03 & $(-0.05,-0.01)$ & 0.002 & 0.00 & $(-0.07,0.07)$ & 0.999 & -3.64 & $(-12.89,5.62)$ & 0.441 & -0.05 & $(-0.11,0.00)$ & 0.057 \\
\hline 3 -day average ${ }^{d}$ & -0.06 & $(-0.09,-0.02)$ & 0.001 & 0.02 & $(-0.09,0.12)$ & 0.776 & -3.83 & $(-17.74,10.09)$ & 0.590 & -0.09 & $(-0.17,-0.01)$ & 0.034 \\
\hline 4-day average ${ }^{d}$ & -0.08 & $(-0.12,-0.03)$ & 0.002 & -0.04 & $(-0.19,0.12)$ & 0.654 & 2.82 & $(-20.26,25.90)$ & 0.811 & -0.13 & $(-0.29,0.02)$ & 0.093 \\
\hline 5-day average ${ }^{d}$ & -0.07 & $(-0.11,-0.02)$ & 0.006 & -0.08 & $(-0.25,0.09)$ & 0.337 & 9.62 & $(-15.47,34.70)$ & 0.452 & -0.10 & $(-0.29,0.08)$ & 0.267 \\
\hline
\end{tabular}

$\mathrm{Cl}$, confidence interval; $\mathrm{O}_{3}$, ozone; $\mathrm{NO}_{2}$, nitrogen dioxide; $\mathrm{SPM}$, suspended particulate matter.

aTest day: The 24-hour mean concentration of a pollutant collected on the day that respiratory function tests were done.

bPrevious day: The 24-hour mean concentration of a pollutant collected on the day before the respiratory function tests were done.

c2-day average: The mean concentration of a pollutant collected on the day and the day before the respiratory function tests were done.

d 3- to 5-day average: The mean concentration of a pollutant collected on the day and the 2 to 4 days before the respiratory function tests were done.

All models are adjusted for temperature and relative humidity.

A

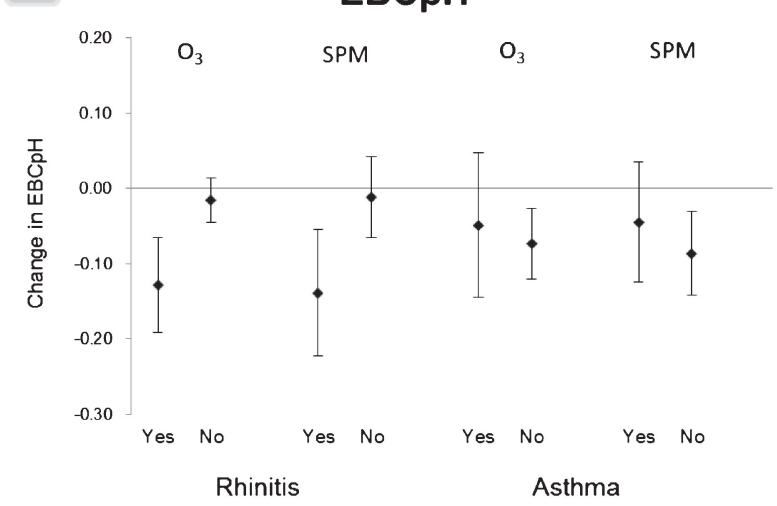

C

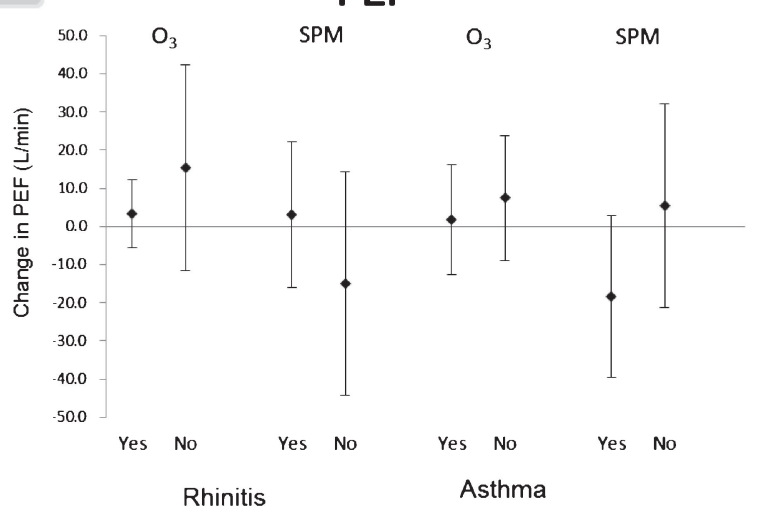

B

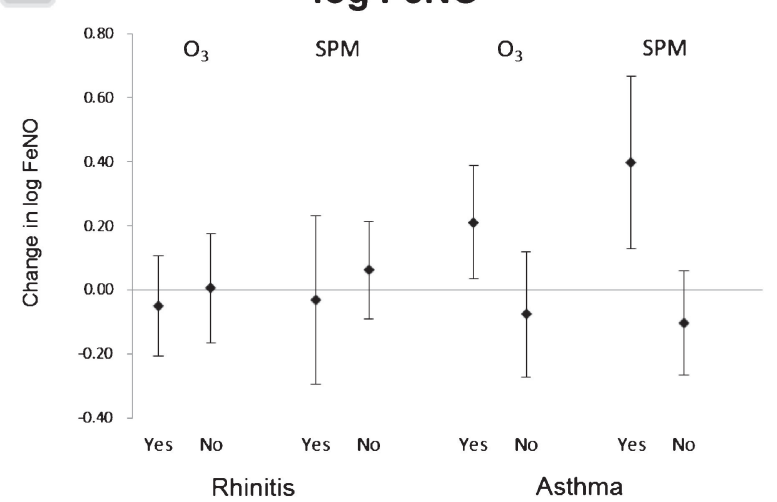

D

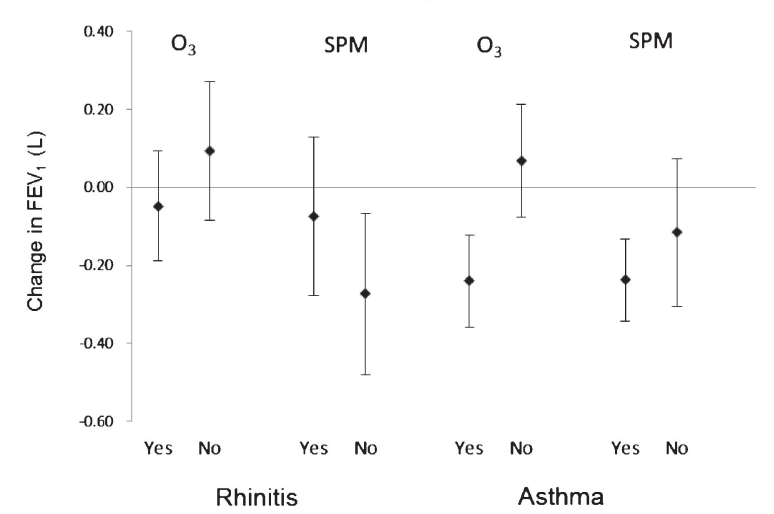

Figure 3. Estimated changes and $95 \%$ Cls in $E B C$ pH (A), log FeNO (B), PEF (C), and FEV 1 (D) with increases in air pollutants. The concentrations of the pollutants were averaged over 4 days, including the day of and 3 days before the respiratory function tests. 
Table 4. Estimated changes and $95 \%$ Cls in respiratory function test results per $10-\mu \mathrm{g} / \mathrm{m}^{3}$ or $10-\mathrm{ppb}$ increase in each single- and two-pollutant model

\begin{tabular}{|c|c|c|c|c|c|c|c|c|c|c|c|c|}
\hline & \multicolumn{3}{|c|}{$\mathrm{EBC} \mathrm{pH}$} & \multicolumn{3}{|c|}{$\log \mathrm{FeNO}$} & \multicolumn{3}{|c|}{ PEF (L/min) } & \multicolumn{3}{|c|}{$\mathrm{FEV}_{1}(\mathrm{~L})$} \\
\hline & Change & $95 \% \mathrm{Cl}$ & $P$ value & Change & $95 \% \mathrm{Cl}$ & $P$ value & Change & $95 \% \mathrm{Cl}$ & $P$ value & Change & $95 \% \mathrm{Cl}$ & $P$ value \\
\hline \multicolumn{13}{|l|}{$\mathrm{O}_{3}$} \\
\hline Single & -0.07 & $(-0.11,-0.03)$ & 0.001 & 0.00 & $(-0.18,0.18)$ & 0.999 & 5.64 & $(-8.69,19.98)$ & 0.440 & 0.01 & $(-0.12,0.14)$ & 0.880 \\
\hline$+\mathrm{NO}_{2}$ & -0.07 & $(-0.11,-0.03)$ & 0.001 & 0.02 & $(-0.19,0.23)$ & 0.851 & 6.27 & $(-9.82,22.35)$ & 0.445 & 0.00 & $(-0.15,0.15)$ & 0.991 \\
\hline +SPM & -0.05 & $(-0.09,-0.01)$ & 0.008 & 0.03 & $(-0.23,0.29)$ & 0.837 & 6.73 & $(-21.78,35.24)$ & 0.644 & 0.12 & $(-0.09,0.32)$ & 0.277 \\
\hline \multicolumn{13}{|l|}{$\mathrm{NO}_{2}$} \\
\hline Single & -0.01 & $(-0.05,0.03)$ & 0.479 & -0.21 & $(-0.52,0.11)$ & 0.200 & -5.41 & $(-30.41,19.59)$ & 0.672 & 0.10 & $(-0.13,0.33)$ & 0.401 \\
\hline$+\mathrm{O}_{3}$ & 0.00 & $(-0.05,0.05)$ & 0.979 & -0.21 & $(-0.56,0.14)$ & 0.242 & -6.66 & $(-33.73,20.42)$ & 0.630 & 0.10 & $(-0.16,0.36)$ & 0.448 \\
\hline+ SPM & 0.01 & $(-0.02,0.04)$ & 0.456 & -0.21 & $(-0.59,0.16)$ & 0.266 & -6.97 & $(-34.69,20.76)$ & 0.622 & 0.16 & $(-0.10,0.42)$ & 0.236 \\
\hline \multicolumn{13}{|l|}{ SPM } \\
\hline Single & -0.08 & $(-0.12,-0.03)$ & 0.002 & -0.04 & $(-0.19,0.12)$ & 0.654 & 2.82 & $(-20.26,25.90)$ & 0.811 & -0.13 & $(-0.29,0.02)$ & 0.093 \\
\hline$+\mathrm{O}_{3}$ & -0.04 & $(-0.08,0.00)$ & 0.078 & -0.06 & $(-0.31,0.20)$ & 0.666 & -2.27 & $(-41.99,37.45)$ & 0.911 & -0.22 & $(-0.47,0.03)$ & 0.088 \\
\hline$+\mathrm{NO}_{2}$ & -0.08 & $(-0.13,-0.03)$ & 0.001 & 0.02 & $(-0.20,0.24)$ & 0.876 & 4.58 & $(-19.86,29.02)$ & 0.713 & -0.17 & $(-0.37,0.02)$ & 0.079 \\
\hline
\end{tabular}

$\mathrm{Cl}$, confidence interval; $\mathrm{O}_{3}$, ozone; $\mathrm{NO}_{2}$, nitrogen dioxide; SPM, suspended particulate matter.

The concentrations of pollutants were averaged over 4 days including the same day and the 3 days before the respiratory function tests were done. All models are adjusted for temperature and relative humidity.

the 4-day average concentrations of each pollutant. EBC $\mathrm{pH}$ showed a significant decrease in relation to 4-day average concentrations of $\mathrm{O}_{3}$ after adjustment for $\mathrm{NO}_{2}$ or SPM concentrations, as well as in the single-pollutant models. On the other hand, the association between EBC pH and SPM concentration was not significant after adjustment for $\mathrm{O}_{3}$ concentrations, while the associations were significant in the single- and two-pollutant model with SPM and $\mathrm{NO}_{2}$. The associations of the other outcomes with the 4-day average concentrations of air pollutants were not significant in either the single- or two-pollutant models.

\section{DISCUSSION}

In this panel study, increases in $\mathrm{O}_{3}$ and SPM in the neighborhood of the subjects' residence were significantly associated with airway inflammation, as reflected by decreases in EBC $\mathrm{pH}$. Furthermore, increase in the 3-day average concentrations of SPM was associated with a decrease in $\mathrm{FEV}_{1}$. Inhalation of $\mathrm{O}_{3}$ causes airway inflammation, wheezing, dyspnea, and damage to pulmonary function. ${ }^{24}$ It has been reported that an increase in $\mathrm{O}_{3}$ concentrations was associated with a decrease in $\mathrm{EBC} \mathrm{pH},{ }^{19}$ which is consistent with the present results. Furthermore, exposure to particulate matter is known to affect pulmonary dysfunction. ${ }^{25}$ However, conflicting findings have also been reported. For example, Maestrellie et al reported that no associations were found between short-term exposure to particulate matter and lung function or inflammatory responses in asthmatic adults. ${ }^{26} \mathrm{In}$ the present study, increased SPM was significantly associated with decreased $\mathrm{EBC} \mathrm{pH}$ and $\mathrm{FEV}_{1}$ in healthy subjects. For $\mathrm{NO}_{2}$, there was no significant association with any measure in the present study. The previous studies reported that EBC $\mathrm{pH}$ among adolescents and asthmatic adults was not affected even by $\mathrm{NO}_{2}$ concentrations higher than those observed in this study. ${ }^{19,26}$
Findings on the short-term effects of air pollutants on airway inflammation markers have not always been consistent. The present study results showed that the changes in EBC $\mathrm{pH}$ were greater in relation to the 4-day average concentration of $\mathrm{O}_{3}$ and SPM than to the concentrations on the same day or the previous day, suggesting the strong effects of the 4-day average concentration of these air pollutants on the respiratory system. Patel et al reported that multiday average concentrations of black carbon were more strongly associated with EBC $\mathrm{pH}$ than shorter averaging times. ${ }^{19}$ Exposures accumulated over multiple days may have a greater effect on airway inflammation. The temporal relationship between exposure to air pollution and airway inflammation should be further evaluated.

In the present study, the daily average concentrations of $\mathrm{O}_{3}$ and SPM changed markedly during the study period, but the time courses of each pollutant were similar across the participants. Therefore, these pollutants were considered to be spread widely over the Tokyo metropolitan area. On the other hand, the concentrations of $\mathrm{NO}_{2}$ differed among participants, which is suggestive of the effects of local emissions.

$\mathrm{FEV}_{1}$ has been widely used as a method for evaluating the effect of air pollutants on lung function. Previous studies reported that decreases in $\mathrm{FEV}_{1}$ were associated with increased exposure to particulate matter. ${ }^{27,28}$ In the present study, $\mathrm{FEV}_{1}$ was negatively associated with SPM concentrations, and the association was strongest among subjects with a history of asthma. This result is considered to be consistent with the findings of Delfino et $\mathrm{al}^{3}{ }^{3}$ who reported stronger associations between particulate matter exposures and $\mathrm{FEV}_{1}$ decrements among children with asthma.

$\mathrm{EBC}$ can be noninvasively collected to evaluate airway inflammation, ${ }^{17}$ and $\mathrm{EBC} \mathrm{pH}$ has been proposed as a biomarker of inflammation that reflects the acid-base balance of the airway, which is regulated primarily by epithelial 
ammonia production and lining fluid proton-buffering. ${ }^{29}$ Vaughan et al demonstrated that measurement of EBC $\mathrm{pH}$ is a simple, robust, and reproducible assay and a relevant marker of airway inflammation. ${ }^{30} \mathrm{EBC} \mathrm{pH}$ values have been reported to be significantly lower in patients with moderate asthma than in mild asthma patients and control subjects. ${ }^{31}$ Recently, Patel et al found that increases in black carbon concentrations were associated with decreases in EBC $\mathrm{pH} .{ }^{19}$

In the present study, EBC $\mathrm{pH}$ was significantly lower with increased $\mathrm{O}_{3}$ or SPM concentrations, and the associations were prominent among subjects with a history of rhinitis. Subjects with a history of rhinitis may also have airway inflammation along with nasal mucosal inflammation. On the other hand, decreases in EBC pH were significantly associated with increases in $\mathrm{O}_{3}$ and SPM concentrations, independent of a history of asthma. Epton et al reported that there was no effect of air pollution on $\mathrm{EBC} \mathrm{pH}$ in patients with asthma and healthy subjects, although they measured EBC $\mathrm{pH}$ immediately after collection without degassing. ${ }^{4}$ In the present study, EBC $\mathrm{pH}$ was measured after degassing with argon, and the effects by air pollutants were observed even among healthy subjects without asthma.

8-Isoprostane has been used as a marker of oxidative stress. ${ }^{32}$ In the present study, however, values of 8-isoprostane in $\mathrm{EBC}$ were below the detection limit in most samples. Because the subjects of our study were healthy young women with little sign of airway inflammation, it may not have been possible to detect 8-isoprostane in their EBC.

FeNO is produced by inducible nitric oxide synthase in the bronchial epithelia constituting the mucous membranes of the airway. ${ }^{33}$ The measurement of FeNO concentrations is used as a method of assessing airway inflammation. ${ }^{34,35}$ In previous studies, it has been reported that increases in FeNO concentrations are associated with exposure to air pollution. ${ }^{8}$ In the present study, FeNO concentrations increased significantly with increased $\mathrm{O}_{3}$ and SPM concentrations only among subjects with a history of asthma, despite the limited number of subjects with such a history. This result was similar to the results of a previous study. ${ }^{15}$ On the other hand, Modig et al recently reported that the effect of $\mathrm{NO}_{2}$ on FeNO was stronger than the effect of $\mathrm{O}_{3}$ in subjects with asthma. ${ }^{36}$

In contrast, we found that FeNO concentrations decreased with increases in $\mathrm{NO}_{2}$ concentrations. This result is inconsistent with those of Delfino et al, who reported that FeNO concentrations increased with increases in $\mathrm{NO}_{2}$ concentration. ${ }^{37}$ This discrepancy may be due to differences in the variation of $\mathrm{NO}_{2}$ concentrations during the study period. In the present study, $\mathrm{NO}_{2}$ concentrations varied among study areas, but the change in the concentrations during the study period was relatively small for most subjects. It is possible that the effects of air pollutants on FeNO differ in relation to the type of air pollutants and exposure conditions.

The present study has several limitations. First, the concentrations of air pollutants in the monitoring stations in the vicinity of the subjects' residences were used to assess exposure to air pollutants. Therefore, it was not possible to accurately assess the subjects' personal exposure levels. Delfino et al suggested that ambient levels of air pollutants might not accurately reflect the exposure to pollutants caused by fossil fuel combustion. ${ }^{37}$ However, the subjects in this study attended the same university, and a large difference was not observed in the variation of concentrations of air pollutants in the subjects' residential areas. Furthermore, all of the subjects were also confirmed through their daily records to have stayed in the Tokyo metropolitan area throughout the study period. Second, the study period was only two weeks, and the changes in pulmonary function and airway inflammation may have been physiological. However, $\mathrm{O}_{3}$ and SPM concentrations changed markedly during the period, and $\mathrm{EBC} \mathrm{pH}$ decreased in relation to the increase in $\mathrm{O}_{3}$ and SPM concentrations. Third, the statistical power was not adequate due to the limited number of subjects. However, all 21 subjects participated in four measurements during the study period, and the results of 84 measurements were evaluated. Therefore, the acute effects of $\mathrm{O}_{3}$ and SPM were observed despite the relatively small number of subjects. Fourth, it was not possible to evaluate the interaction by respiratory symptoms of the subjects. Respiratory symptoms, such as cough, phlegm, and wheezing, were evaluated by a standard questionnaire, but few subjects had such symptoms because they were healthy students.

In the present study, healthy young adult women were the target subjects. We believe that all people in urban districts may suffer the effects of air pollution on health in daily life. Therefore, we would like to perform a study in a larger, more varied population of healthy subjects. In particular, the effects of air pollutants among males should be evaluated, because the subjects of this study were only females.

In conclusion, the present study showed that increases in $\mathrm{O}_{3}$ or SPM concentrations were associated with decreased pulmonary function and decreased $\mathrm{EBC} \mathrm{pH}$. Subjects with a history of rhinitis showed greater changes in $\mathrm{EBC} \mathrm{pH}$ with increases in $\mathrm{O}_{3}$ and SPM concentrations. In addition, subjects with a history of asthma showed higher FeNO levels with increased $\mathrm{O}_{3}$ concentrations. These results suggest that subjects with a history of rhinitis or asthma are especially susceptible to the harmful effects of air pollution. Because this study involved a small number of subjects, the effects of short-term exposure to air pollutants should be further evaluated in a larger study.

\section{ONLINE ONLY MATERIALS}

eTable 1. Estimated changes and $95 \%$ CIs in the respiratory function test results per $10-\mu \mathrm{g} / \mathrm{m}^{3}$ or $10-\mathrm{ppb}$ increase in each pollutant during the study period among the 17 subjects who lived less than $5 \mathrm{~km}$ from the monitoring stations.

Abstract in Japanese. 


\section{ACKNOWLEDGEMENTS}

This work was supported in part by a Grant-in-Aid for Scientific Research (A) (No. 23249034) from the Japan Society for the Promotion of Science (JSPS). The authors would like to thank the study subjects and the staff of Otsuma Women's University for their technical support.

Conflicts of interest: None declared.

\section{REFERENCES}

1. Brunekreef B, Holgate ST. Air pollution and health. Lancet. 2002;360:1233-42.

2. Rojas-Martinez R, Perez-Padilla R, Olaiz-Fernandez G, Mendoza-Alvarado L, Moreno-Macias H, Fortoul T, et al. Lung function growth in children with long-term exposure to air pollutants in Mexico City. Am J Respir Crit Care Med. 2007; 176:377-84.

3. Delfino RJ, Staimer N, Tjoa T, Gillen D, Kleinman MT, Sioutas $\mathrm{C}$, et al. Personal and ambient air pollution exposures and lung function decrements in children with asthma. Environ Health Perspect. 2008;116:550-8.

4. Epton MJ, Dawson RD, Brooks WM, Kingham S, Aberkane T, Cavanagh JA, et al. The effect of ambient air pollution on respiratory health of school children: a panel study. Environ Health. 2008;7:16.

5. Jaffe DH, Singer ME, Rimm AA. Air pollution and emergency department visits for asthma among Ohio Medicaid recipients, 1991-1996. Environ Res. 2003;91:21-8.

6. Ma L, Shima M, Yoda Y, Yamamoto H, Nakai S, Tamura K, et al. Effects of airborne particulate matter on respiratory morbidity in asthmatic children. J Epidemiol. 2008;18:97-110.

7. Mann JK, Balmes JR, Bruckner TA, Mortimer KM, Margolis $\mathrm{HG}$, Pratt B, et al. Short-term effects of air pollution on wheeze in asthmatic children in Fresno, California. Environ Health Perspect. 2010;118:1497-502.

8. Mar TF, Jansen K, Shepherd K, Lumley T, Larson TV, Koenig JQ. Exhaled nitric oxide in children with asthma and short-term PM2.5 exposure in Seattle. Environ Health Perspect. 2005;113: 1791-4.

9. Yamazaki S, Shima M, Ando $M$, Nitta $H$, Watanabe $H$, Nishimuta T. Effect of hourly concentration of particulate matter on peak expiratory flow in hospitalized children: a panel study. Environ Health. 2011;10:15.

10. Balmes JR. The role of ozone exposure in the epidemiology of asthma. Environ Health Perspect. 1993;101 Suppl 4:219-24.

11. Gielen MH, van der Zee SC, van Wijnen JH, van Steen CJ, Brunekreef B. Acute effects of summer air pollution on respiratory health of asthmatic children. Am J Respir Crit Care Med. 1997;155:2105-8.

12. McConnell R, Berhane K, Gilliland F, London SJ, Islam T, Gauderman WJ, et al. Asthma in exercising children exposed to ozone: a cohort study. Lancet. 2002;359:386-91.

13. Mortimer KM, Neas LM, Dockery DW, Redline S, Tager IB. The effect of air pollution on inner-city children with asthma. Eur Respir J. 2002;19:699-705.

14. Berhane K, Zhang Y, Linn WS, Rappaport EB, Bastain TM,
Salam MT, et al. The effect of ambient air pollution on exhaled nitric oxide in the Children's Health Study. Eur Respir J. 2011;37:1029-36.

15. Khatri SB, Holguin FC, Ryan PB, Mannino D, Erzurum SC, Teague WG. Association of ambient ozone exposure with airway inflammation and allergy in adults with asthma. J Asthma. 2009;46:777-85.

16. American Thoracic Society; European Respiratory Society. ATS/ ERS recommendations for standardized procedures for the online and offline measurement of exhaled lower respiratory nitric oxide and nasal nitric oxide, 2005. Am J Respir Crit Care Med. 2005;171:912-30.

17. Horváth I, Hunt J, Barnes PJ, Alving K, Antczak A, Baraldi E, et al. Exhaled breath condensate: methodological recommendations and unresolved questions. Eur Respir J. 2005;26:523-48.

18. Liu L, Poon R, Chen L, Frescura AM, Montuschi P, Ciabattoni $\mathrm{G}$, et al. Acute effects of air pollution on pulmonary function, airway inflammation, and oxidative stress in asthmatic children. Environ Health Perspect. 2009;117:668-74.

19. Patel MM, Chillrud SN, Deepti KC, Ross JM, Kinney PL. Traffic-related air pollutants and exhaled markers of airway inflammation and oxidative stress in New York City adolescents. Environ Res. 2013;121:71-8.

20. Ferris BG. Epidemiology Standardization Project (American Thoracic Society). Am Rev Respir Dis. 1978;118:1-120.

21. Yoda Y, Otani N, Hasunuma H, Kanegae H, Shima M. Storage conditions for stability of offline measurement of fractional exhaled nitric oxide after collection for epidemiologic research. BMC Pulm Med. 2012;12:68.

22. Katanoda K, Sobue T, Satoh H, Tajima K, Suzuki T, Nakatsuka $\mathrm{H}$, et al. An association between long-term exposure to ambient air pollution and mortality from lung cancer and respiratory diseases in Japan. J Epidemiol. 2011;21:132-43.

23. Liang KY, Zeger SL. Longitudinal data analysis using generalized linear models. Biometrika. 1986;73:13-22.

24. U.S.EPA. Air Quality Criteria for Ozone and Related Photochemical Oxidants (EPA 600/R-05/004aF-cF). Research Triangle Park, NC: U.S. Environmental Protection Agency; 2006.

25. U.S.EPA. Air Quality Criteria for Particulate Matter (EPA/600/P99/002aF-bF). Research Triangle Park, NC: U.S. Environmental Protection Agency; 2004.

26. Maestrelli P, Canova C, Scapellato ML, Visentin A, Tessari R, Bartolucci GB, et al. Personal exposure to particulate matter is associated with worse health perception in adult asthma. J Investig Allergol Clin Immunol. 2011;21:120-8.

27. Delfino RJ, Quintana PJ, Floro J, Gastañaga VM, Samimi BS, Kleinman MT, et al. Association of $\mathrm{FEV}_{1}$ in asthmatic children with personal and microenvironmental exposure to airborne particulate matter. Environ Health Perspect. 2004;112:932-41.

28. Trenga CA, Sullivan JH, Schildcrout JS, Shepherd KP, Shapiro GG, Liu LJ, et al. Effect of particulate air pollution on lung function in adult and pediatric subjects in a Seattle panel study. Chest. 2006;129:1614-22.

29. Hunt JF, Erwin E, Palmer L, Vaughan J, Malhotra N, Platts-Mills TA, et al. Expression and activity of pH-regulatory glutaminase in the human airway epithelium. Am J Respir Crit Care Med. 2002;165:101-7. 
30. Vaughan J, Ngamtrakulpanit L, Pajewski TN, Turner R, Nguyen TA, Smith A, et al. Exhaled breath condensate $\mathrm{pH}$ is a robust and reproducible assay of airway acidity. Eur Respir J. 2003;22: 889-94.

31. Kostikas K, Papatheodorou G, Ganas K, Psathakis K, Panagou $\mathrm{P}$, Loukides S. pH in expired breath condensate of patients with inflammatory airway diseases. Am J Respir Crit Care Med. 2002;165:1364-70.

32. Janssen LJ. Isoprostanes: an overview and putative roles in pulmonary pathophysiology. Am J Physiol Lung Cell Mol Physiol. 2001;280:L1067-82.

33. Ricciardolo FL. Multiple roles of nitric oxide in the airways.
Thorax. 2003;58:175-82.

34. Barnes PJ, Belvisi MG. Nitric oxide and lung disease. Thorax. 1993;48:1034-43.

35. Kharitonov SA, Barnes PJ. Exhaled markers of pulmonary disease. Am J Respir Crit Care Med. 2001;163:1693-722.

36. Modig L, Dahgam S, Olsson D, Nyberg F, Wass K, Forsberg B, et al. Short-term exposure to ozone and levels of exhaled nitric oxide. Epidemiology. 2014;25:79-87.

37. Delfino RJ, Staimer N, Gillen D, Tjoa T, Sioutas C, Fung K, et al. Personal and ambient air pollution is associated with increased exhaled nitric oxide in children with asthma. Environ Health Perspect. 2006;114:1736-43. 